\title{
دراسة بعض المتغيرات المرتبطة بالمستوى المعرفي لمربي الاسماك في حوض نهر الغرّاف في جمهورية العراق
}

\section{أبوزيد محمد الحبال سوزلن إبراهيم الثريتلي مصطفي لطفي صبري قسم الإقتصاد الزراعي - كلية الزراعة (سابا باشا) - جامعة الإسكندرية}

الملخص : بستهدف هذا البحث بصفة رئيسية التعرف على بعض المتغييرات المرتبطة بالمستوى المعرفي لمربي الأسماك في حوض نهر الغرّاف في جمهورية العراق، ولقد إعنمد الباحث على الإستبيان بالمقابلة الثخصية

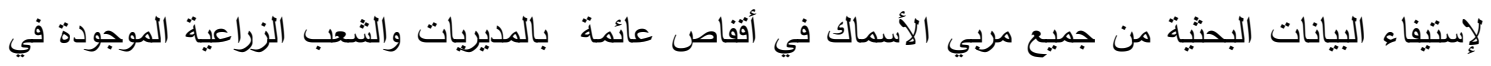
حوض نهر الغراف بالعراق والبالغ عددهم (123) مربي ، وقد تمثلت الأساليب الإحصائية التحليلية المستخدمة

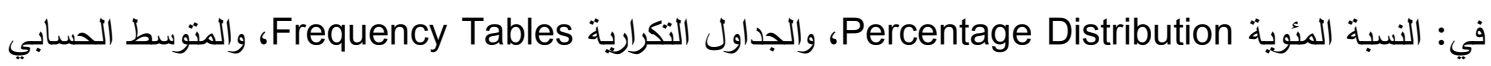
Arithmetic Mean ، وذلك لإظهار التباين بين المبحوثين، كما إستخدم للتحقق من صدق الفروض البحثية معامل الإرتباط البسيط Correlation Coefficient لبيرسون لدراسة العلاقات الإرتباطية بين المتغيرات المستقلة والمتغير التابع وذللك بإستخدام الحاسب الآلي بإستخدام برنامج( SPSS ) (الحزمة الإحصائية للعلوم الإجتماعية )

$$
\text { وقد أوضحت النتائج البحثية ما يلي: }
$$

أولاً: الخصائص الشخصية والإجتماعية - الإقتصادية والإتصالية والنفسية لمربي الأسماك المبحوثين : فيما

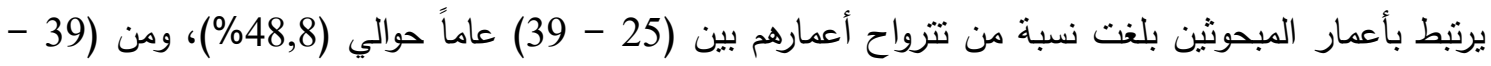

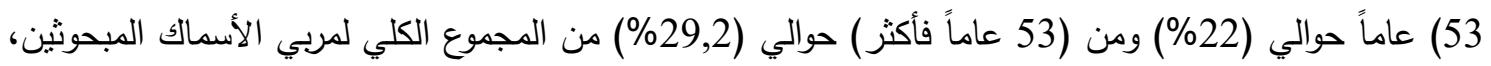

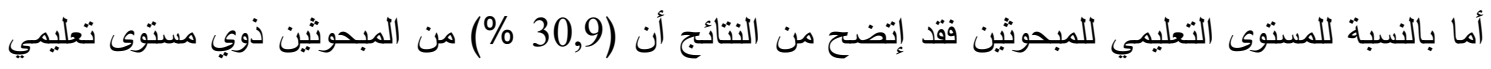
منخفض، وأن (52\%) ذوي مستوى تعليمي منوسط في حين كان (17,1\%) من المبحوثين ذوي مسنوى تعليمي

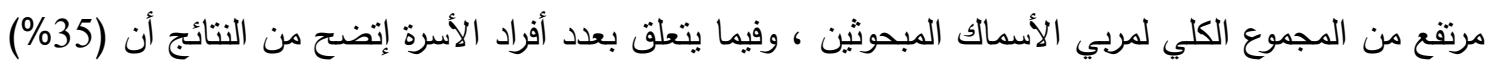
من ذوي الأسر الصغيرة، وأن (57,7\%) من ذوي الأسر المتوسطة في حين كان (7,3\%) من ذوي الأسر الكبيرة بعند

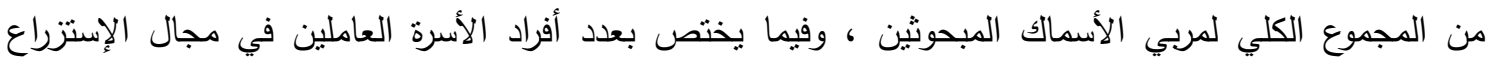

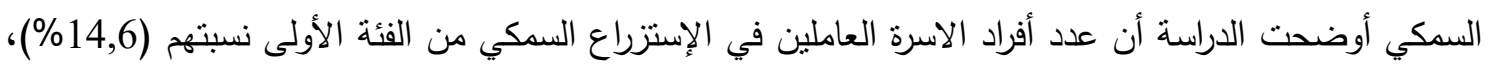

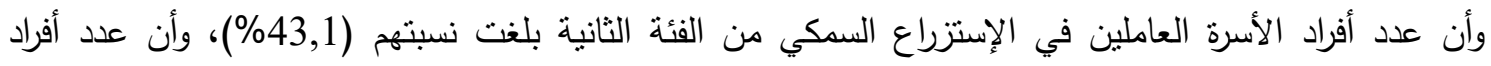

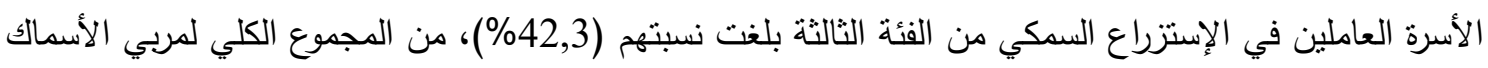
المبحوثين ، وفيما يرتبط بالخبرة السمكية للمبحوثين فبلغت نسبة من تترواح عدد سنوات خبرتهم بين (1-

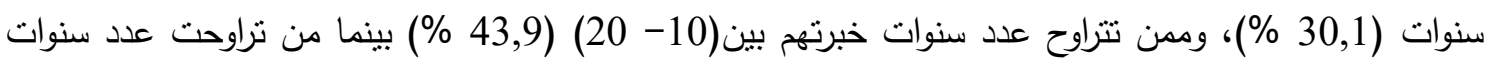
خبرتهم من (20 سنة فأكثر) (26\%) من المجموع الكلي للمربي الأسماك المبحوثين ، أما بالنسبة للدخل السنوي من الإنتاج السمكي أوضحت الدراسة أن الذين ينسمون بدخل منخفض بلغت بنت نسبتهم (1,6\%)، بينما ذوي الدخل المتوسط بلغت نسبتهم (76,4 \% )، وذوي الدخل المرتفع بلغت نسبتهم (22\%) من المجموع الكلي لمربي الأسماك للمبحوثين ، وفيما يختص بالسعة الحيازية من الأقفاص السمكية العائمة أوضحت الدراسة أن نسبة مربي الأسماك لاك المبحوثين الذين ينسمون بحيازة مزرعية صغيرة (56,1\%)، والمتوسطة (25,2\%)، والمرتفعة (18,7\%) من المجموع الكلي 
لمربي الأسماك المبحوثين ، وفيما يرتبط بمتوسط إنتاج القفص من الأسماك فقد أوضحت الدراسة أن نسبة المربين من

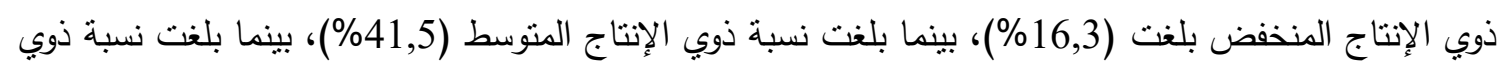
الإنتاج المرتفع (42,3\%) من المجموع الكلي لمربي الأسماك المبحوثين ، أما بالنسبة لمصادر المعلومات الزراعية الإنية

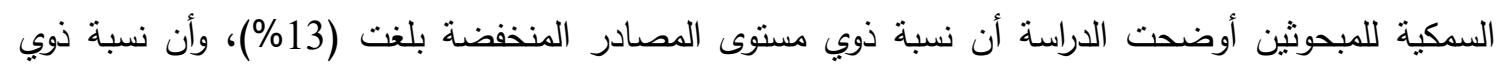
المصادر المنوسطة بلغت (73,2\%)، في حين بلغت نسبة ذوب المستوى المرتفع (13,8\%) من المجموع الكلي

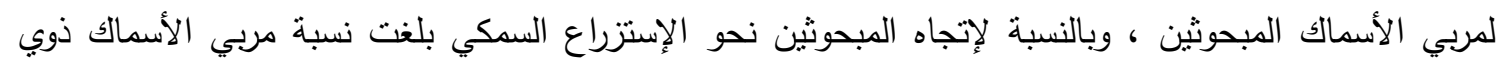

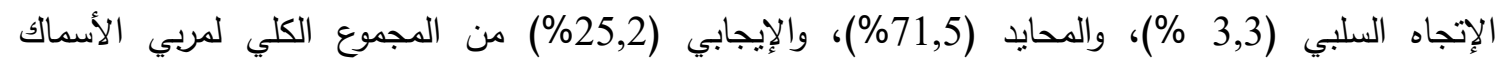
المبحوثثن.

ثانيـاً: المستوى المعرفي العـام لمريسي الأسـماك المبحـثين: أوضـت الدراسـة أن نسبة ذوبي المستوى المعرفي

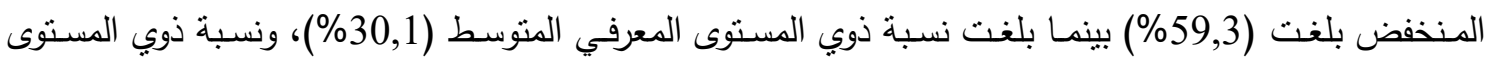
المرتفع بلغت (10,6\%) من المجموع الكلي لمربي الأسماك المبحوثين.

ثالثاً: العوامل المرتبطة بالمستوى المعرفي لمربي الأسماك المبحوثين: أوضحت النتائج وجود علاقة إرتباطية

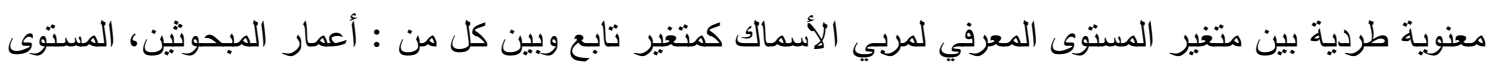
التعليمي، عدد أفراد الأسرة، عدد أفراد الأسرة العاملين في الإستزراع السمكي، الخبرة السمكية للمبحوثين، الدخل

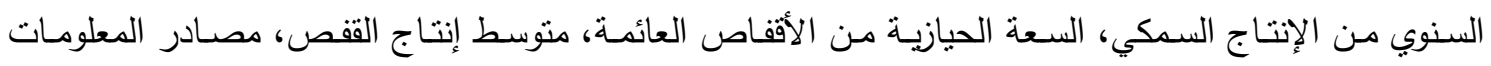
الزراعية السمكية للمبحوثين، إتجاه المبحوثين نحو الإستزراع السمكي.

رابعاً: المشكلات التي تواجه مريسي الأسماك المبحوثين من وجهة نظرهم: أوضحت الدراسة وجود ستة مشاكل

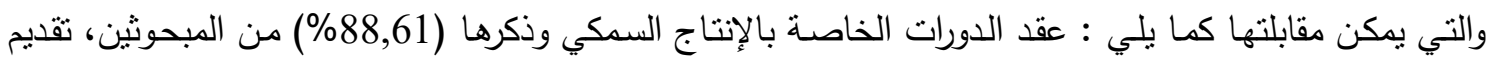
القروض الميسرة لمربي الأسماك وذكرها (88,61\%) من المبحوثين ، توفير الأعلاف ورخص أسعارها وذكرها (82,92\%) من المبحوثين، توفير الإصبعيات ورخص أسعارها وذكرها (74,79\%) من المبحوثين، المواد الأولية وتوفيرها وقد ذكرها (69,10\%) من المبحوثين، الروتين الحكومي وقد ذكرها (43\%) من المبحوثين.

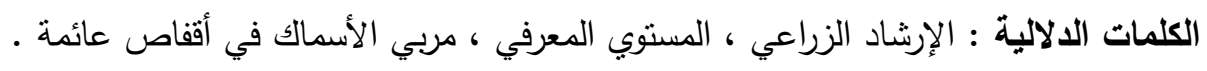

\section{المقدمة والمشكلة البحثية:}

تعتبر الأسماك أحد مصادر البروتين الحيواني الهامة التي تحتوي على قيمة غذائية عالية، كما أنها تعتبر مصدراً للاهون الضرورية والفيتامينات والمعادن، كما أن كيلو واحد من الأسماك يغطي إحتباجات الفرد من اليود الئين لمدة خمسين يوماً، وقد أثنارت الدراسات العلمية الى أن نحو (200 غم) من لحوم الأسماك تكفي إحتباجات الفرد

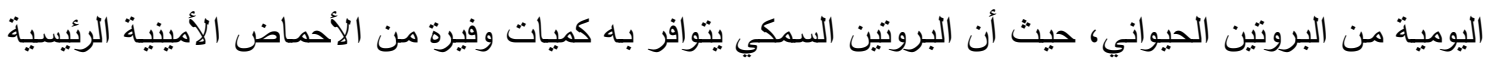

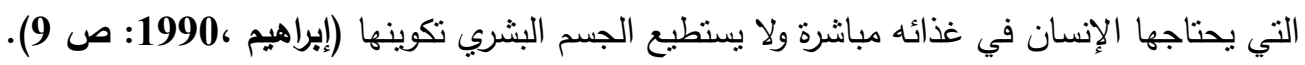
كما تعتبر الأسماك من الحيوانـات الأكثر كفاءة في تحويل غذائها الى أنسجة، فقد وجد أن أحد أنواع الأسماك (التراوت) عندما يغذى على غذاء عالي الجودة فإن كل (1,5 كيلو غرام) من الغذاء يتحول الى (كيلوغرام) 
من اللحم السمكي، كما إن الطاقة اللازمة لإنتاج وحدة من الوزن في الأسماك تكون أقل مما في حالة الحيوانات

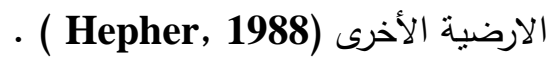

وعلى ذلك يمكن القول أن التوسـع الأفقي والرأسسي في الإستزراع السمكي يمكن أن يلعب دوراً حيوياً في توفير إحتباجات السكان من البروتين الحيواني وتقليل حجم الفجوة الغذائية وخفض الواردات بصفة عامة من اللحوم

( EL- Ghmrini, 1998:p258) والأسماكئ

هذا ويبلـغ إنتاج العراق من الثروة السمكية (المزارع السمكية ومسن الأنهار والصبد البحري) عام 2005

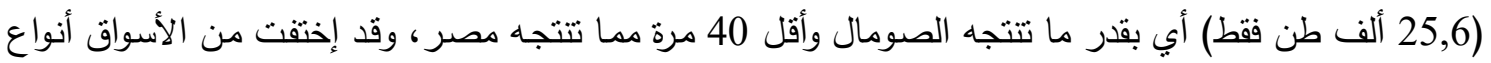
رئيسية من الأسماك العراقية كالبني والكطان والثبوط وإنخفض إنتاج الثروة السمكية من (36935 طن) عام 1997

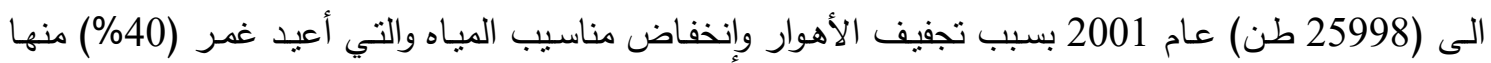
بالمياه منذ عام (2003)، إضـافة الى الممارسـات الخاطئة التي بستخدمها بعض الصبادين كالسموم التي تقتل أعداد كبيرة من الأسماك، وعدم إلتزام الصبادين بمنع الصبد خلال موسم التكاثز مع عدم توفر الأعلاف والأدوية

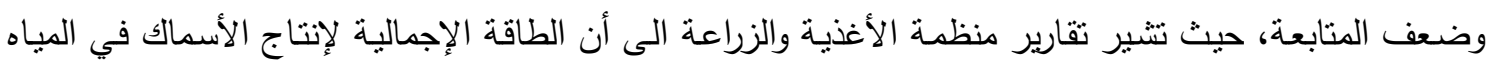
العذبة أخذت بـالهبوط المستمر حيث تراوحت ما بين (13,6) و (12,3) ألف طن بين عامي 2000 و 2004. وتتكل أسماك الكارب الإعنبادي الجزء الأكبر من المحتوى السمكي لمسطحات المياه الداخلية للعراق، يأني بعدها الكطان، والثبوط، والبني، والأحمر، والثنلك، والبز ، والجري، وهناك أسماك أخرى غير إقتصادية كأسماك الخشني

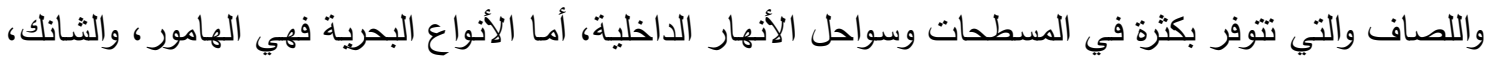

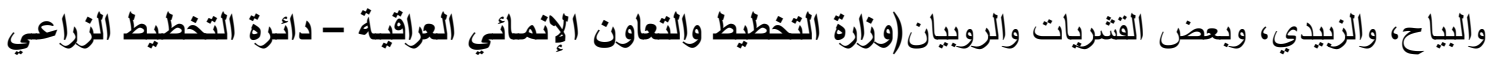
. 10:2009، ،

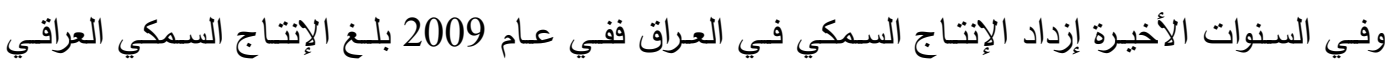
حوالي(321,5 طن)، وإرتفع عام 2010 إلى (32438 طن) وفي عام 2011 بلغ (54,99 ألف طن) حيث تقدر مقسمة إلى (39,76 الف طن) من المصائد و (15,23 الف طن) من المزارع وهذه الكميات لاتكفي لسد حاجات

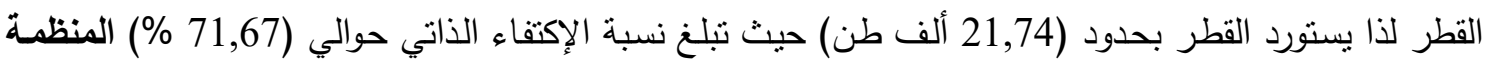
العربية للتنمية الزراعية ، (2011 ) ، الكتاب السنوي للإحصاءات الزراعية،الخرطوم، السودان ل

إن التـدهور المرحلـي واضـح حيـث تـنـي إنتاجيـة الــونم الواحــــــن الأسـماك في المســحات المائيـة

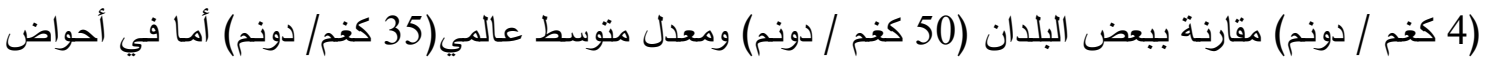
التربية فتبلغ الإنتاجية (500 كغم / دونم) أما الإرتفاع النسبي في إنتاج لحوم الأسماك فيرجع الى كثرة التجاوزات

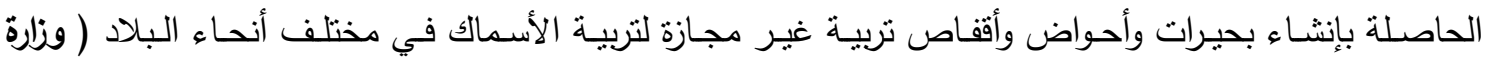

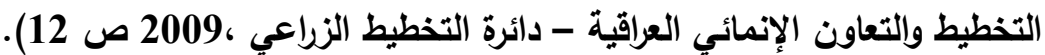

وبالرغم من إهتمام الدولة بتتمية وتطوير المزارع السمكية وبذل المزيد من الجهود لزيادة الإنتاج السمكي

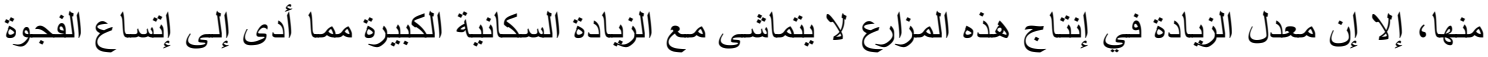

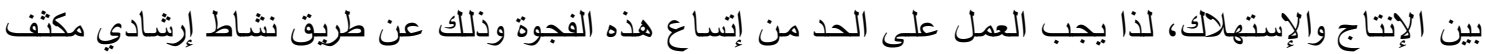
يعظم الإستفادة من هذه المزارع ويعمل على مد حائزيها بالمعارف والمعلومات الكفيلة بزيادة إنتاجها. 
ويستطيع الإرشاد الزراعي بإعتباره عملية تعليمية نستهف إحداث تغييرات مرغوبة في معارف ومهارات

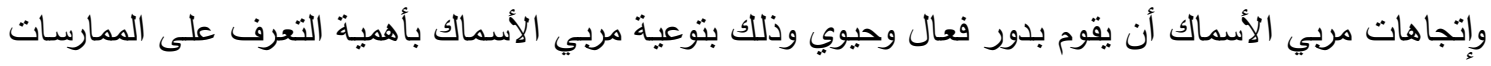

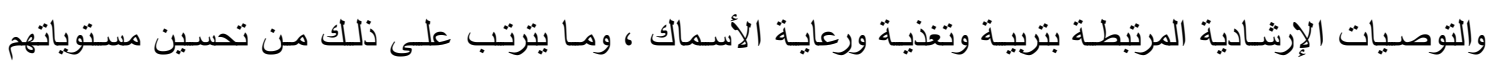

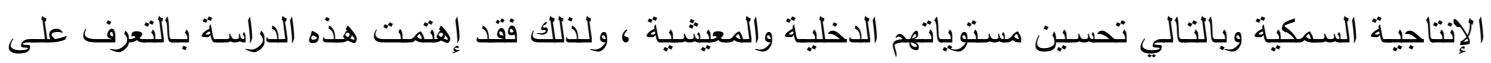

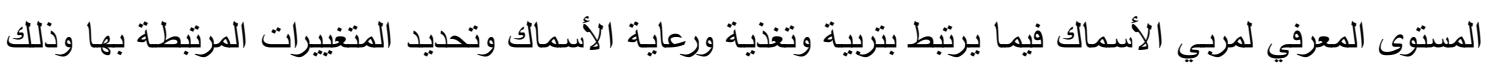

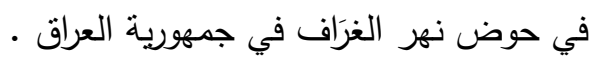

\section{الأهداف البحثية:}

يستهدف هذا البحث التعرف على بعض المتغييرات المرتبطة بالمستوى المعرفي لمربي الأسماك في حوض نهر الغرّاف في جمهورية العراق، ويمكن تحقيق هذا الهدف من خلال تحقيق الأهداف الآتية :

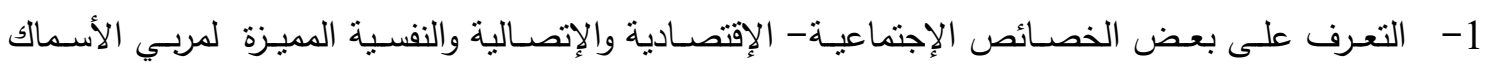
المبحوثين.

2- ت تحديد بعض المتغيرات المرتبطة بالمستوى المعرفي لمربي الأسماك المبحوثين.

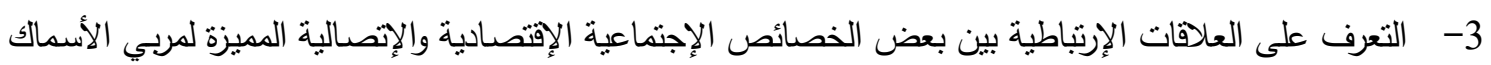

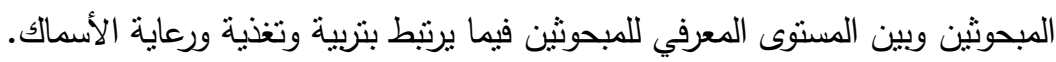
4- تحديد المشكلات التي نواجه مربي الأسماك المبحوثين ومقترحاتهم لحلها من وجهائ نظرهم.

\section{الإستعراض المرجعي:}

مفهوم المعرفة: - مفي

يرى عمر وآخرون ( 1973 ، ص : 53) أن المعرفة هي " القدر من المعلومات التي يحوزها الفرد والتي

تمكنه من ربط علاقات ما بين الظواهر المختلفة بما ينسنى معه سهولة إدراكها وسرعة إستيعابها ".

في حين يرى حسن (1990، ص :60) أن المعرفة " لا تقتصر على ظواهر من لون معين بل تنتاول

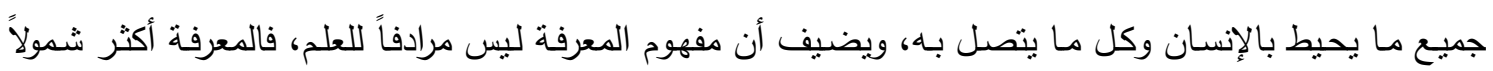
وأوسع حدوداً من العلم حيث تتضمن معارف علمية وغير علمية ".

ويذكر أبو السعود ( 1987، ص:351) أن المعرفة هي " جميع المعلومات والخبرات التي أدركها الإنسان وإستوعبها عن طريق حواسه ويستطيع أن يسترجعها في أي وقت من الأوقات ".

بينما يرى سيد ( 1989، ص:35 ) أن المعرفة هي " إحاطة العلم بالثيء وهي تنتاول جميع ما يحيط

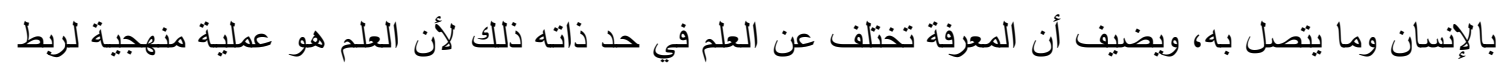

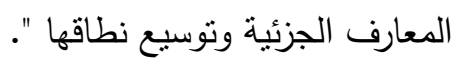

ويذكر حسن (1990، ص :20) أن المعرفة هي " مجموعة من المعاني والتصسورات والآراء والمعتقدات

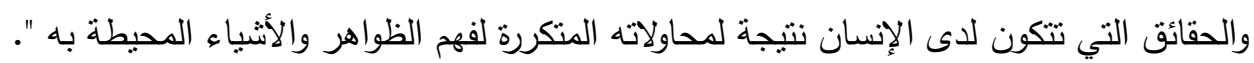


ويعرف السيا (1990: ص: 14) المعرفة على أنها " كل ما إستقر في ذهن الإنسان من معانٍ وخبرات

أمكن إكتسابها عن طريق حواسه المختلفة ".

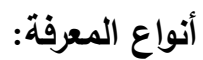

تعددت المراجع والدراسـات العلمية التي قامت بتصنيف المعرفة وتتاولت أنواعها، فقد صنف عمر وآخرون

(1973، ص :54) المعرفة الى نوعين : معارف علمية، ومعارف غير علمية، وإن التقرقة بينهما نكون على أساس قواعد المنهج المستخدم وأساليب التقكير التي تنتع في تحصيل المعارف. : معاف

بينما يرى جامع ( 1975، ص :114) أن هنالك نوعين من المعرفة هما :

1- المعرفة الواقعية : التي نتواجد في الواقع العملي للحياة.

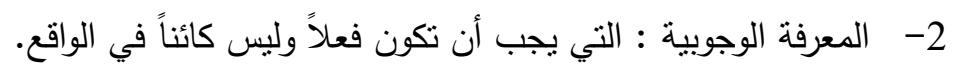

ويرى عمر( 1978، ص : 14،13) أن المعرفة يمكن تصنيفها الى ثلاثة أنواع هي :

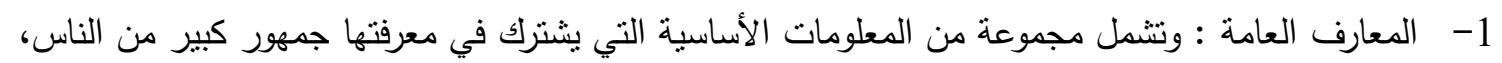

وهي تساهم في تكوين إطار معرفي تنبي عليه كثير من المعارف التخصصية الاخرى، وهي نتشمل مجموعة

مقررات أساسية في مجالات العلوم الطبيعية والإجتماعية والإنسانية.

2- المعارف المتخصصـة: وتتشمل مجموعـة من المعلومـات التخصصية في مجال معين، والتي تكون الركيزة

الأساسية للإطار النظري الذي يبنى عليه كثير من النطبيقات المنية الأخرى.

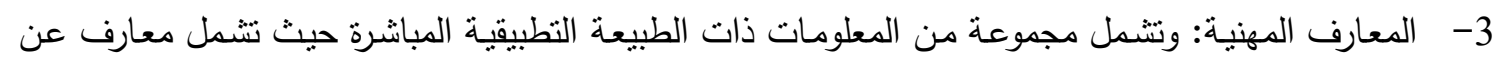

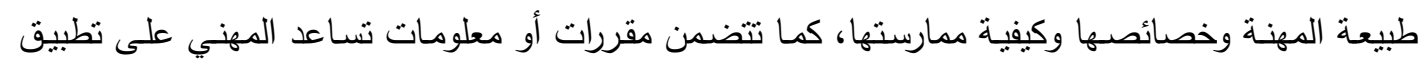

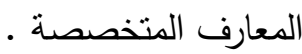

ويرى سيد ( 1989، ص : 36،35) أن هناك ثناثة أنواع من المعرفة هي :

1- المعرفة الحسية: وهي التي تقتصر على الملاحظة البسيطة للظواهر المختلفة ولا تتعدى مستوى الإدراك

الحسي العادي.

2- المعرفة الفلسفية: وهي التي تقوم على الإسلوب القياسي وتتتاول الظواهر بالبحث والدراسة وتتجه بالبحث إلى

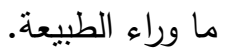

3- المعرفـة العلميـة: وهي التي تقوم على الإسـلوب الإسـتقرائي الذي يعتمد على المنهج العلمي والملاحظـة

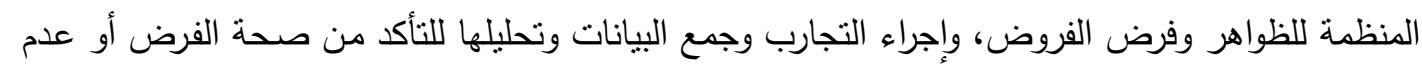

صحنه.

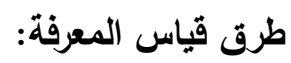

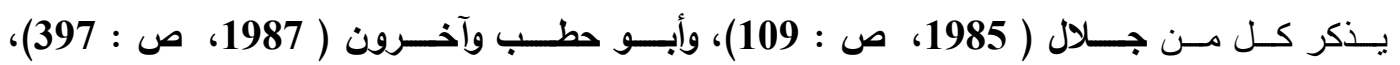

والنجار(1991، ص : 89 )، أنه يمكن قياس المعرفة عن طريق إختبارات التحصيل والتي يمكن إيجازها فيما يلي

1- إختبار الإستدعاء البسيط : ويهذف الى إستدعاء الفرد لما تم حفظه.

2- إختبار الصواب والخطأ : وهو عبارة عن أسئلة يبين الفرد فيها الصواب واءل والخطأ.

Vol. 19 (4), 2014 
3- إختبار أسئلة البديلين : ويتطلب إجابة واحدة من بين إجابتين.

4- إختبار الإختبار المتعدد : حيث يختار الفرد الإجابة الصحيحة من عدة إجابات محتملة.

5- إختبار إتمام الجمل : وفيه يكمل الفرد الجملة الناقصة بكلمة أو مجموعة من الكلمات.

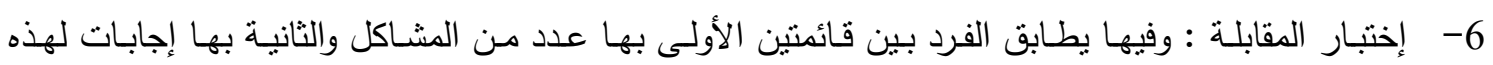
المشاكل ولكن بترتيب مخالف ويطلب من الفرد أن يربط كل مشكلة من القائهة الأولى مـع حلها في القائمسة

الثانية .

7- إختبار الحصر : وفيه يقوم الفرد بحصر بعض النقاط التي يجب أن تنوافر في موضوع معين.

8- إختبار أسئلة الترتيب : وفيه يقوم الفرد بترتيب خطوات أو إجراءات أو أحداث في تسلسل منطقي.

التصنيفات المعرفية:

لقد صنف بلوم وآخرون (Bloom et al.,1956 ) المجال المعرفي ضمن ست فئات رئيسية كما يذكرها توق وآخرون ( 2007 ، ص : 43) هي :

1- المعرفة (التذكر) : ويقصد بها تذكر المادة التي تم تعلمها سابقاً، وقد يتضمن هذا إستدعاء عدد كبير من المواد إبتذاءاً من الحقائق البسيطة وإنتهاءاً بالنظريات، إلا أن كل ما هو مطلوب هو إستعادة المعلومات المناسبة، وتمثل هذه الفئة أدنى مسنويات النواتج التعليمية في البعد المعرفي.

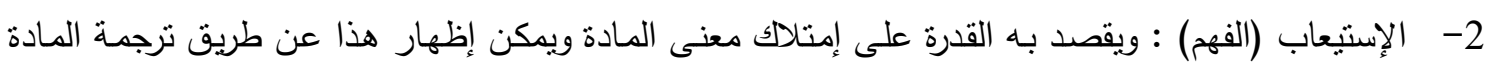
من شكل الى شكل آخر (الكلمات إلى أرقام) أو عن طريق إتجاهات المستقبل (التتبؤ عن النتائج أو الآثار ). إن هذه النتاجات التعليمية أصعب بقليل من مجرد التذكر ، وتمثل أدنى مستوى من مستويات الفهم.

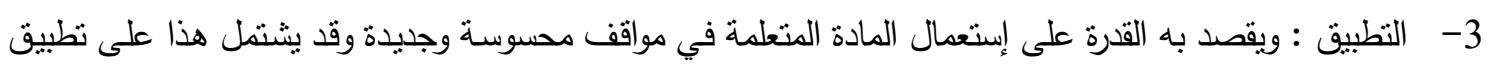

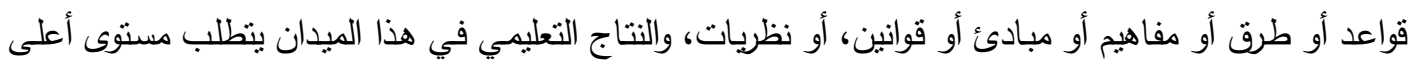
من الفهم من ذلك الذي ينطلبه الإستيعاب أو الفهم. 4- التحليل : ويقصد به القدرة على تجزئة مادة ما إلى عناصرها المكونة لها، لكي يتتسى فهم البناء التتظيمي لتلك المسادة وقد يشتمل هذا على تعيين الأجزاء، وتحليل العلاقة بينهما، والتعرف على التى المبادئ التتظيميـة المنتظمة وإن هذا المستوى أعلى من الإستيعاب والنطبيق من حيث أنه يتطلب فهم المحتوى والثكل البنائي للمادة. 5- التركيب : ويقصد بـه القدرة على وضـع الأجزاء مـع بعضها البعض لنتكيل كل جديد، وقد يتضمن هذا إنتاج قطعة فريدة (خطاب موضوع) أو خطة عمليات (مشروع دراسة) أو منظومة علاقات مجردة (خطة لتصنيف معلومات). إن الناتج التعليمي في هذا الميدان يركز على السلوك الإبداعي لتكوين أنماط بنائية جديدة. 6- التقويم : ويقصد بـه القدرة للحكم على قيمة المادة لغرض معين، وهذه الأحكام يجب أن تبنى على معلى معايير

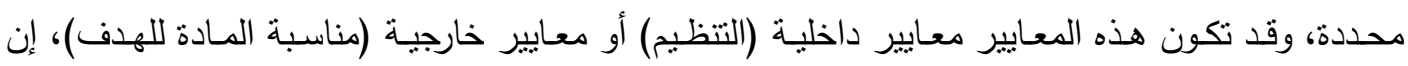

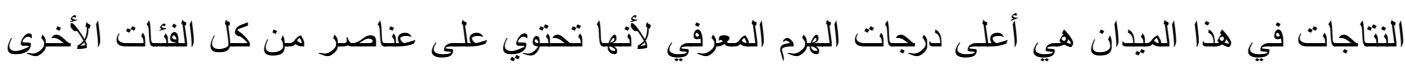
بالإضافة الى حكم القيمة المبني على معايير معرفة تعريفاً دقيقاً. 
تنظم الست فئات أعلاه فيما بينها وفق ترتيب هرمي من الأسهل الى الأصعب ومن البسبط الى المركب، كما

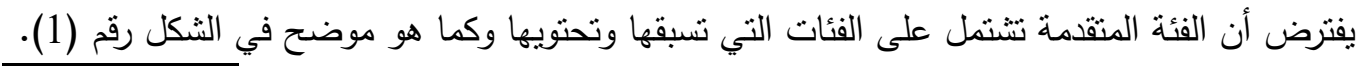

\begin{tabular}{|c|c|c|c|c|c|}
\hline التقويم & & & & & \\
\hline التركيب & التركيب & & & & \\
\hline التحليل & التحليل & التحليل & & & \\
\hline التطبيق & التطبيق & التطبيق & التطبيق & & \\
\hline الإستيعاب & الإستيعاب & الإستيعاب & الإستيعاب & الإستيعاب & \\
\hline المعرفة & المعرفة & المعرفة & المعرفة & المعرفة & المعرفة \\
\hline
\end{tabular}

شكل (1): الترتيب الهري لفئات المجال المعرفي وفقاً لتصنيف بلوم

دور الإرشاد الزراعي في مجال الإستزراع السمكي :

يقوم الإرشـاد الزراعي بدور هـام في تعليم الأفراد كيفية إنثباع إحتياجـاتهم ومسـاعدة أنفسهم على حل

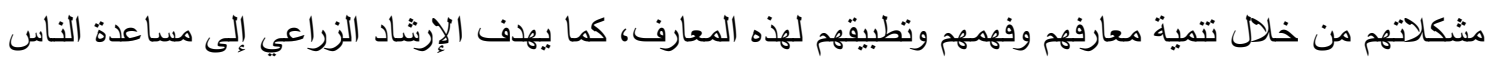
بمدهم بالمعارف لرفع مستواهم الفكري وتعليمهم مهارات جديدة وتغيير إتجاهاتهم ونظرتهم لتقبل الجديد وحفزهم

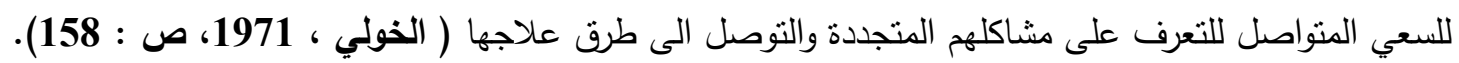
كما يقوم الإرشاد الزراعي أيضاً بدور هام في نشر وتحسين وإنباع الأساليب العلمية عند تطبيق العديد من

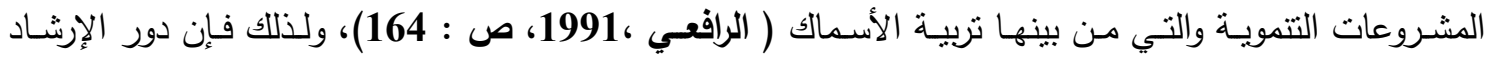
الزراعي في هذا المجال يتبلور في إعداد برامج تتموية تتتاول مجال الإستزراع السمكي، وحث مربي الأسماك على دلى لإنى تطبيق التقنيات الفنية المستحدثة في هذا المجال، وكذا تدريب الكوادر الفنية لتأهيلهم للقيام بالدور الإرشادي وكذا ولتها

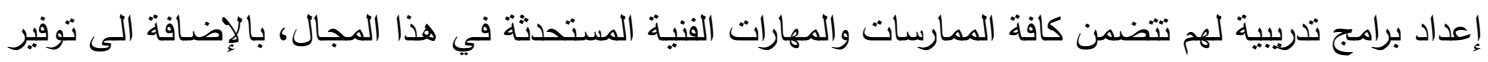

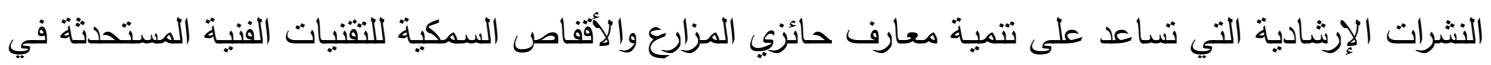

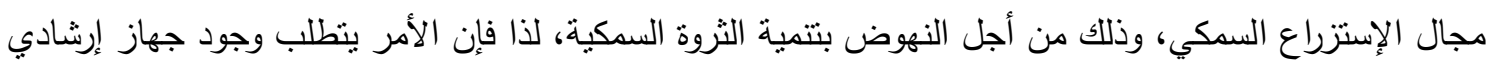

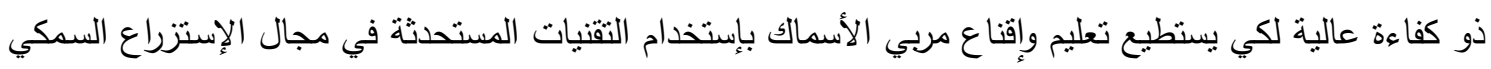
لتطوير إنتاجهم وتحسين أحوالهم المعيشية.

وحيث أن غالبية حائزي المزارع السمكية والصيادين يتسمون بأنهم متمسكون بالأساليب التقليدية في حياتهم وذوي مستوى معيشي منخفض، وقد يكون منهم غير ملمين بالقراءة والكتابة، لذلك فإنه لايمكن تغيير خبراتهم في بالي

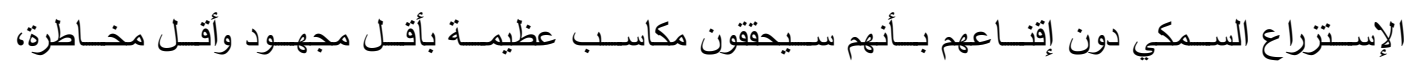

.(Royce,1995:p414) 
والإرشاد الزراعي يمكن أن يقوم بدور مهم في مجال تبني ونقل الأساليب والمبتكرات التكنولوجية السمكية

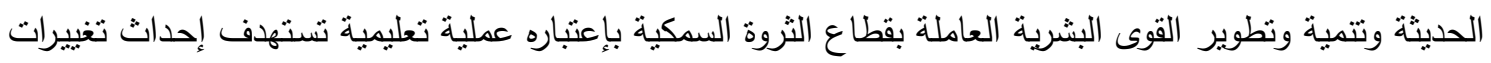

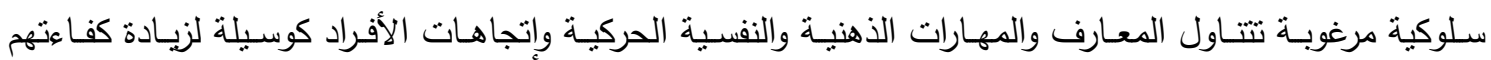

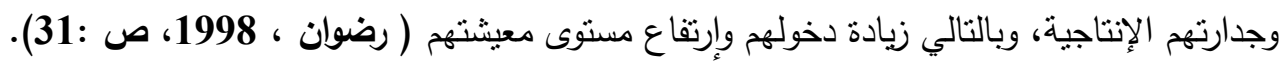
ويعتمد الإششاد السمكي في أدائه على معظم الطرق الإرشادية المتعارف عليها إلا أنه يركز على طرق

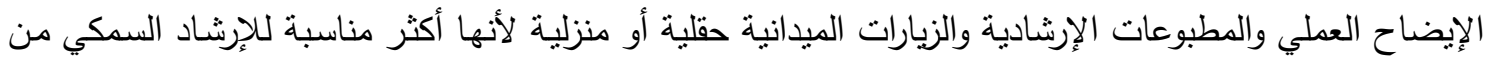

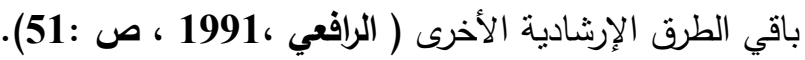

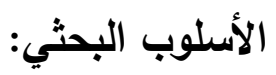

\section{التعريفات الإجرائية للمصطلحات البحثية:}

1- القفص السمكي العائم: يقصد به إطار (خشبي / بلاستيك) محاط بشبكة من الغزل وتحمله براميل بلاستيك الإك

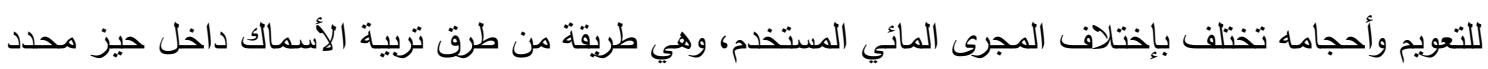
موضوع في مجرى مائي داخلي يمكن السبطرة عليه بأقل التكاليف الممكنة.

2- مريو الأسماك: يقصد بهم في هذا البحث كل من يحوز قفصاً سمكياً أو أكثر ويقع ضمن منطقة البحث.

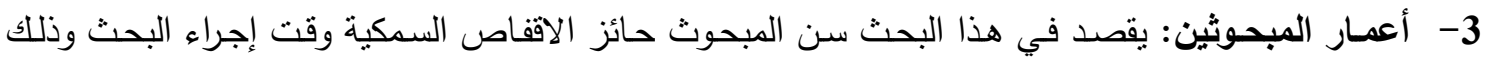
لأقرب سنة .

4- المستوى التعليمي للمبحوث: يقصد في هذا البحث الحالة التعليمية وقت إجراء البحث من حيث أنه أمي أو

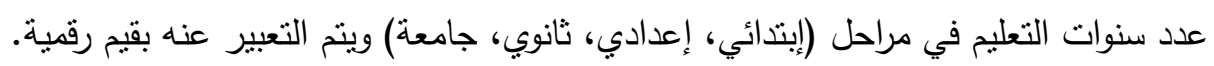

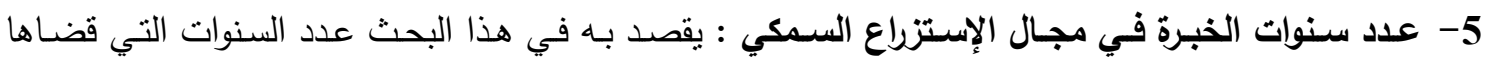
المبحوث في تربية الأسماك.

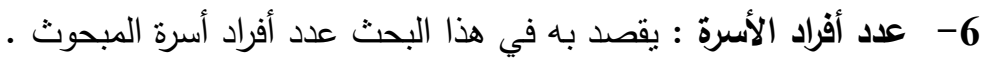
7- عدد أفراد الأسرة العاملين في مجال الإستزراع السمكي : ويقصد به في هذا البحث عدد أفراد أسرة المبحوث الذين يعاونونه في مجال الإستزراع السمكي. 8- حجم القفص بـالمتر المكعب : يقصد بـه في هذا البحث حاصل ضرب أبعاد القفص الطول * العرض * العمق في المياه. 9- الدخل السنوي من الإنتاج السمكي : ويقصد به في هذا البحث قيمة إنتاج الأسماك من الإنتاج السمكي سنوياً مقدرة بالدينار العراقى. 10- السعة الحيازيـة للمبحوث من الأقفاص السمكية : يقصد بـه في هذا البحث كمية الأقفاص التي يمتلكها المبحوث مقدرة بقيمة عددية. 11- متوسط إنتاج القفص من الأسماك : يقصد بـه في هذا البحث كمية الأسماك الموجودة في الققص مقدرة

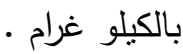

12- التعرض لمصادر المعلومـات : يقصد به في هذا البحث مدى تعرض المبحوث للمصادر التي يرجع إليها عندما نواجهه مشكلة ما في مجال الإستزراع السمكي. 
13- الإتجاه نحو تربية الاسماك في الاقفاص السمكية : يقصد به في هذا البحث ميل وإستعداد المبحوث نحو فكرة نربية الأسماك في الأقفاص السمكية العائمة. 14- المستوى المعرفي للمبحوثين فيما يرتبط بتربية وتغذية ورعاية الأسماك: يقصد به في هذا البحث حصيلة معارف المبحوثين حائزي الأقفاص السمكية العائمة محل الدراسة فيما يرتبط بتربية وتغذية ورعاية الأسماك.

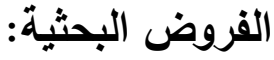
لتحقيق أهداف هذا البحث تم صياغة الفرض البحثي التالي: توجد علاقة إرتباطية بين المستوى المعرفي

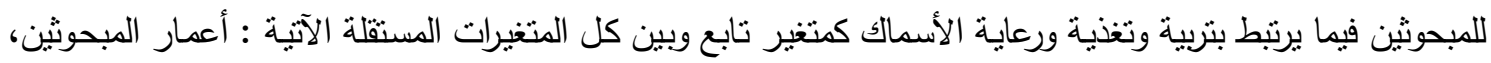

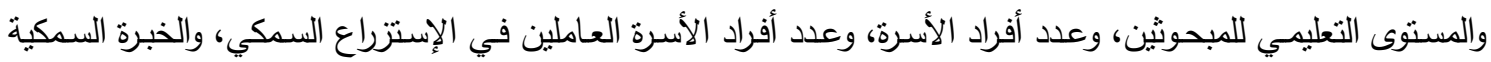

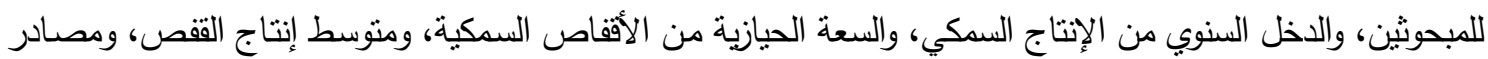

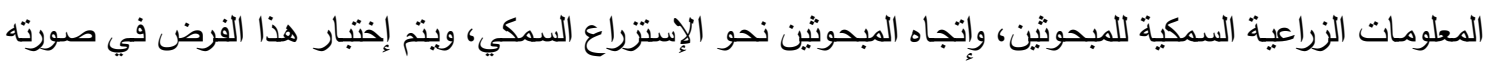
الصفرية (فرض العدم) التالية :"لا توجد علاقة إرتباطية بين المستوى المعرفي للمبحوثين فيما يرتبط بتربية وتغذية ورعاية الإنية الأسماك كمتغير تابع وبين كل من المتغيرات المستقلة المدروسة كلاً على حده.

\section{منطقة البحث:}

وقع الإختيار على منطقة حوض نهر الغرَاف تحديداً كمنطقة لإجراء هذه الدراسـة، وذللك لعدة إعتبارات منطقية كان من أهمها: أن هذه المنطقة تعتبر من المناطق الأكثر إنتاجاً من حيث الإستزراع السمكي بها كما هـا أنها

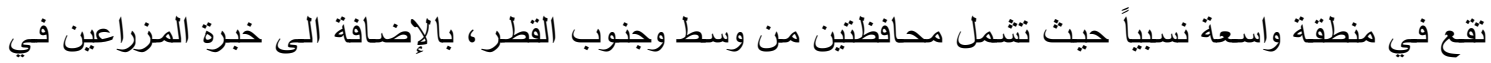

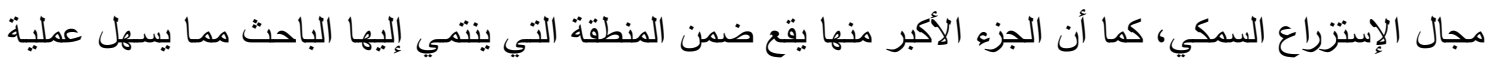

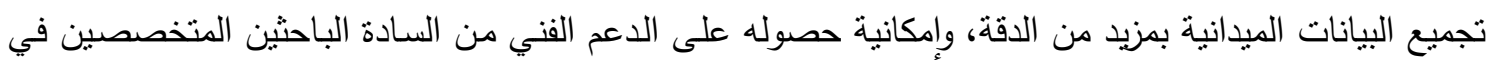
مجال الدراسة بسهولة مما يدعم صحة ودقة النتائج المتحصل عليها.

\section{الشاملة والعينة:}

تمنلات شـاملة هذه الدراسـة في جميع مربسي الأسماك في أقفاص عائمـــ بالمديريات والثـعب الزراعيـة الموجودة في حوض نهر الغرَاف بالعراق وذلك من واقع سجلات المديريات والثعب الزراعية في تلك المناطق وقد بلغ عدد مربي الأسماك (123) مربي موزعين على المناطق التالية : منهم (20) مزارعاً في الكوت و (10) مزارعين

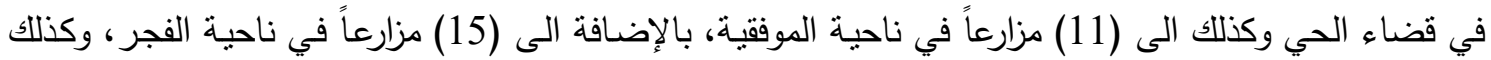
(12) مزارعاً في ناحية قلعة سكرَ، كذلك وجود (17) مزارعاً في قضاء الرفاعي، ووجود (14) مزارعاً في ناحية النصر، ووجود (14) مزارعاً في قضـاء الشطرة بالإضـافة الى (10) مزارعين في ناحيـة الغرَاف، وقد تم أخذهم جميعاً عينة للاراسة وبذلك إنطوت الثناملة على العينة. 


\section{النتائج البحثية والمناقشة:}

أولاً : بعض الخصائص الثخصية والإجتماعية الإقتصادية والإتصالية والتفسية المميزة لمربي الأسماك المبحوثين:

يتضـح من جدول (1) ما يلي : أن غالبية المبحوثين من ذوبي الأعمار الصغيرة (48,8\%) وتلك الفئة تتسم بالحيوية والنشاط وتقبل الممارسات الجديدة في مجال تربية وتغذية ورعاية الأسماك الأمر الذي من شأنه أن أن ينعكس على النهوض بمستوى الإنتاجية وإرتفاع مستوى دخولهم وتحسن أحوالهم المعيشية ، كما تبين إرتفاع نسبة التعليم بين المبحوثين (52\%)، الأمر الذي يساعد كثيراً في تعلمهح وتقبلهم للتوصيات الإرشادية المرتبطة بتربية

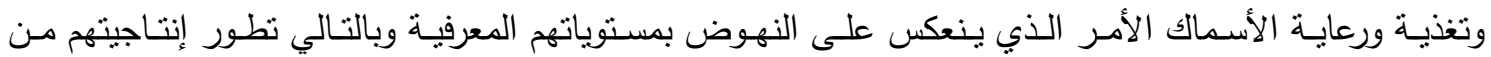
الأسماك ، وقد إتضح كبر السعة الأسرية للمبحوثين (57,7\%) وقد يعزى ذلك الى رغبة المبحوثين إنجاب أعداد كبيرة بأسرهم لمساعدتهم في الأعمال المزرعية السمكية الأمر الذي قد يشجع على التوسع في مساحات الإستزراع السمكي ، في حين تبين إرتفاع نسبة العمالة الأسرية في الإستزراع السمكي(43,1\%) الأمر الذي قد بيساعد كثيراً في تطور إنتاجية الأسرة من الأسماك لتحسين دخولهم وتطور أحوالهم المعيشية ، وقد اتضح أن غالبية المبحوثين ذوي خبرة متوسطة (43,9\%) ، في مجال الإستزراع السمكي، وهذا من شـأنه أن يؤدي الى تقبلهم الكثير من

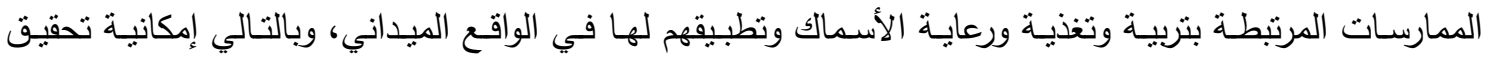

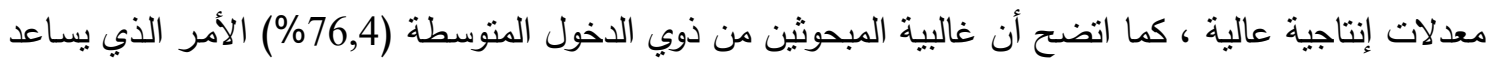

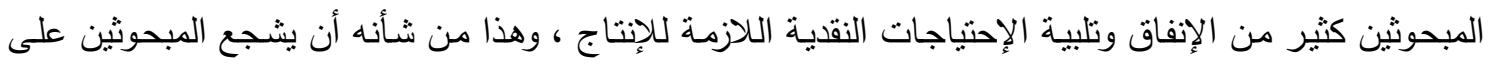

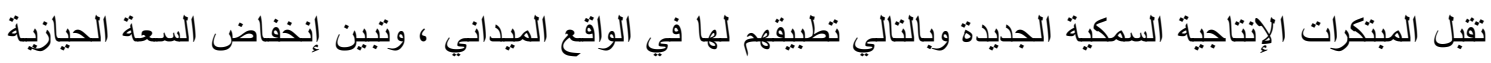

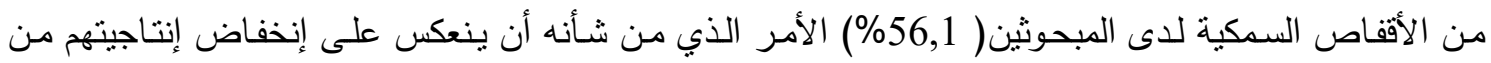
الأسماك وبالتالي إنخفاض دخولهم، وينطلب الأمر من الجهات المعنية تدعيم مربي الأسماك بتوفير مستلزمات

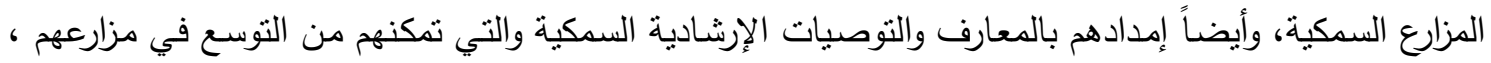
كما تبين أن متوسط إنتاجية قفص الأسماك لدى غالبية المبحوثين ذوي مستوى إنتاج منوسط ومرتفع (41,55)، (42,3) الأمر الذي يثجع كثيراً على إمكانية مزاولة المبحوثين لهذا النشاط الإنتاجي الحيوي، وأيضاً إمكانيـة

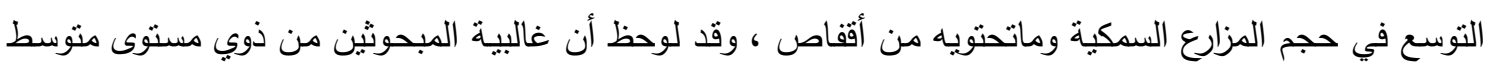

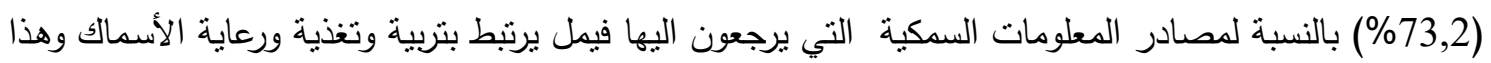

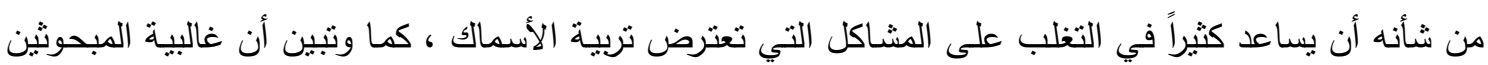
ذوي إتجاه محايد نحو الإستزراع السمكي (71,5\%) الأمر الذي ينطلب من الجهاز الإرشادي السمكي إمداد الزراع

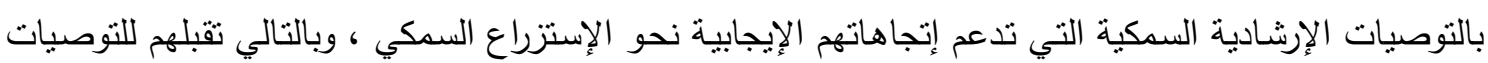

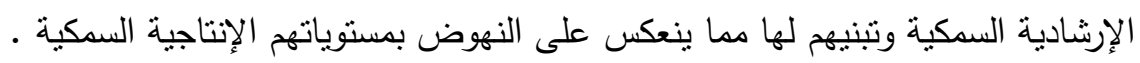


جدول (1): توزيع المبحوثين وفقاً لخصائصهم الثخصية والإجتماعية الإقتصادية والإتصالية والنفسية

\begin{tabular}{|c|c|c|c|c|c|}
\hline$\%$ & العدد & الخصائص & $\%$ & العدد" & الخصائص \\
\hline 1,6 & 2 & 6- الاخل السنوي من الإنتاج السمكي : & $\begin{array}{c}48, \\
8\end{array}$ & 60 & 1 1 أعمار المبحوثين: 25 - 25 - \\
\hline 76,4 & 94 & مستوى دخل متوسط (5 - 9) مليون & $\begin{array}{c}22, \\
0\end{array}$ & 27 & منوسطو السن 39 - 53 \\
\hline 22,0 & 27 & مستوى دخل مرتفع (9 مليون فأكثر) & $\begin{array}{c}29, \\
2\end{array}$ & 36 & كبار السن ( 53 سنة فأكثر) \\
\hline $\begin{array}{l}56,1 \\
25,2\end{array}$ & $\begin{array}{l}69 \\
31\end{array}$ & 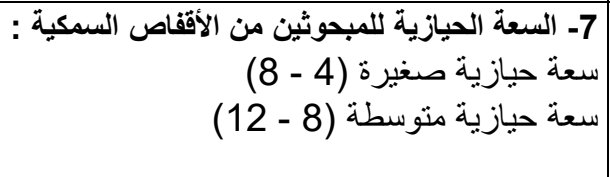 & $\begin{array}{c}30 \\
9 \\
52 \\
0\end{array}$ & $\begin{array}{l}38 \\
64\end{array}$ & مستوى تعليمي منخفض التعليمي للمبحوثين: \\
\hline 18,7 & 23 & سعة حيازية كبيرة (12 قفص فأكثر) & $\begin{array}{c}17, \\
1\end{array}$ & 21 & مستوى تعليمي مرتفع (7 درجات فأكثر) \\
\hline $\begin{array}{l}16,3 \\
41,5 \\
43,9\end{array}$ & $\begin{array}{l}20 \\
51 \\
52\end{array}$ & 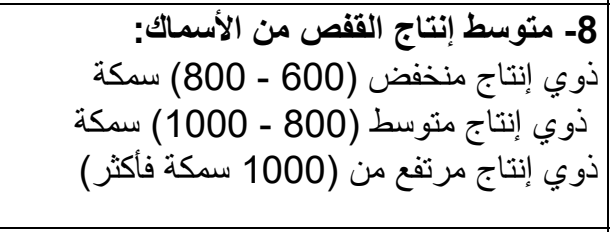 & $\begin{array}{c}35, \\
0 \\
57, \\
7 \\
7,3\end{array}$ & $\begin{array}{c}43 \\
71 \\
9\end{array}$ & 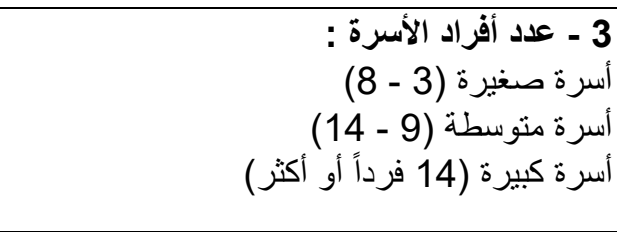 \\
\hline $\begin{array}{l}13,0 \\
73,2 \\
13,8\end{array}$ & $\begin{array}{l}16 \\
90 \\
17\end{array}$ & 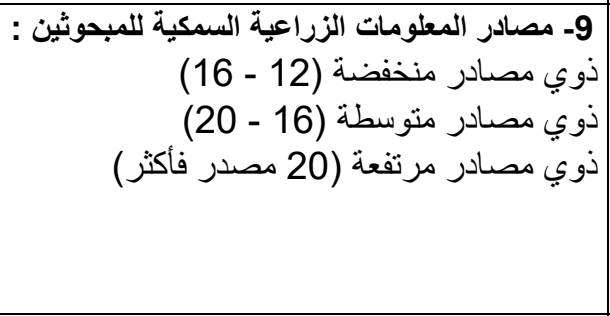 & $\begin{array}{c}14, \\
6 \\
43, \\
1 \\
42, \\
3\end{array}$ & $\begin{array}{l}18 \\
53 \\
52\end{array}$ & 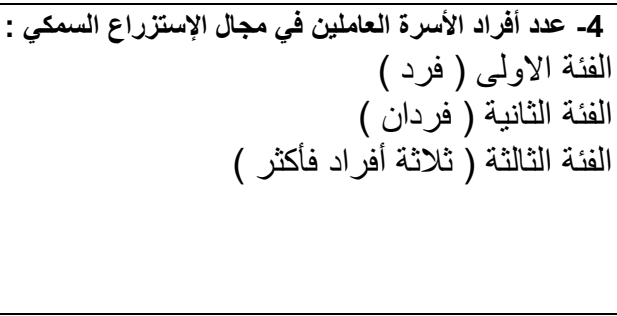 \\
\hline $\begin{array}{r}3,3 \\
71,5 \\
25,2\end{array}$ & $\begin{array}{c}4 \\
88 \\
31\end{array}$ & 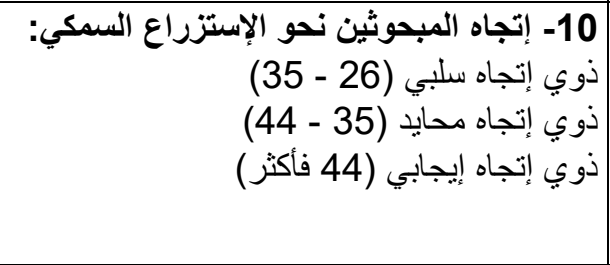 & $\begin{array}{c}30, \\
1 \\
43, \\
9 \\
26, \\
0\end{array}$ & $\begin{array}{l}37 \\
54 \\
32\end{array}$ & 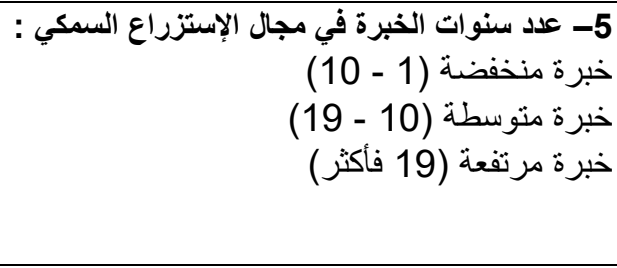 \\
\hline
\end{tabular}

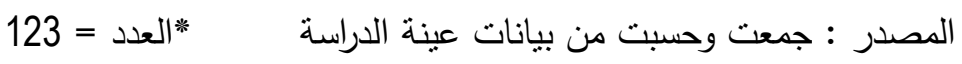

ثانياً: المستوى المعرفي لمربي الأسماك المبحوثين:

يتضح من جدول رقم (2) أن ما يقرب من نصف المبحوثين من صغار السن ، الأمر الذي يساعدهم كثيراً

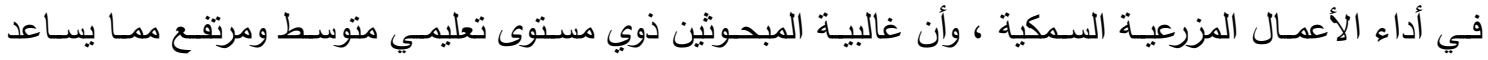
المبحوثين على الإستفادة من التوصيات الإرشـادية السمكية ، هذا بالإضـافة الى غالبيـة المبحوثين تزيد خبرتهم

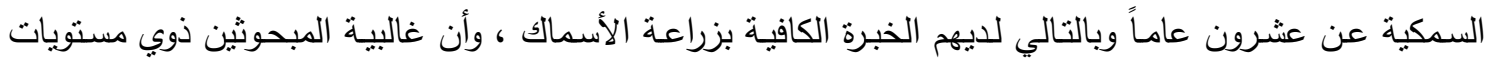

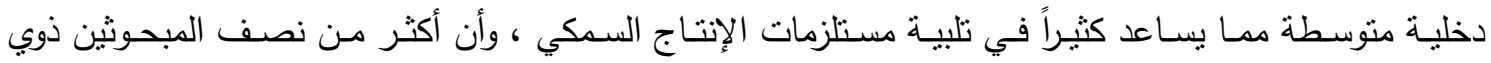

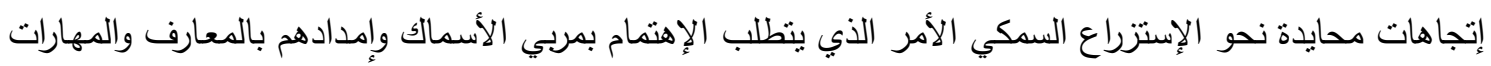

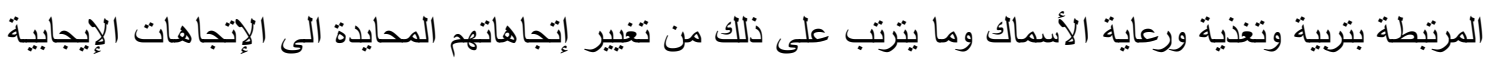

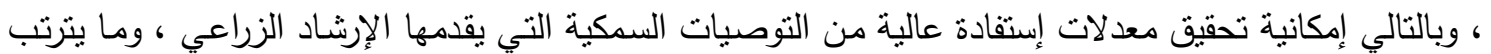
على ذلك من زيادة إنتاجهم ودخولهم • 
جدول رقم (2) : توزيع مربي الأسماك وفقاً لفئات مستواهم المعرفي

\begin{tabular}{|c|c|c|c|c|c|}
\hline$\%$ & العدد & الخصائص & $\%$ & 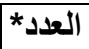 & الخصائص \\
\hline & & 3 - المستوى المعرفي للمبحوثين فيما يرتبط & & & 1- المستوى المعرفي العام للمبحوثين فيما \\
\hline 59,3 & & ذوي مستوى معرفي منخفض (14 - 19) & & & ذوي مستوى معرفي منخفض (55 - 69) \\
\hline 31, & & ل معرفي المتوسط (19 - 24) & & & ذوي مستوى معرفي متوسط (69 - 83) \\
\hline \multirow[t]{2}{*}{8,9} & 11 & ذوي مستوى معرفي مرتفع (24 درجة فأكثر) & 10,6 & & ذوي مستوى معرفي مرتفع (83 درجة فاكثر) \\
\hline & & 4- المستوى المعرفي للمبحوثين فيما يرتبط & & & 2-2 المستوى المعرفي للمبحوثين فيما يرتبط الأسماك \\
\hline 74,0 & & ذوي مستوى معرفي منخفض (11- 5 & & & ذوي مستوى معرفي منخفض (21 - 26) \\
\hline 22,0 & 27 & ذوي مستوى معرفي منوسط (16 - 20) & 45,5 & 56 & ذوي مستوى معرفي متوسط (26 - 31) \\
\hline 4,0 & 5 & ذوي مستوى معرفي مرتفع (21 درجة فاكثر) & 3,2 & 4 & ذوي مستوى معرفي مرتفع (31 - 36) \\
\hline
\end{tabular}

$$
123=\text { العدد }
$$

المصدر : جمعت وحسبت من بيانات عينة الدراسة

ثالثاً: العلاقات الإرتباطية بين كل من المتغيرات المستقلة المدروسة وبين المستوى المعرفي للمبحوثين كمتغير تابع: جدول رقم (3) : يوضح توزيع المتغيرات المستقلة وفقاً لعلاقاتها الإرتباطية البسيطة مع المستوى المعرفي للمبحوثين كمتغير تابع

\begin{tabular}{|c|c|c|}
\hline المستوى المعنوي & معامل الإرتباط البسيط & المتغيرات المستقلة \\
\hline * & 0,227 & أعمار المبحوثين \\
\hline * & 0,071 & المستوى التعليمي للمبحوثين \\
\hline * & 0,142 & عدد أفر اد الأسرة \\
\hline * & 0,138 & عدد أفر اد الأسرة العاملين في الإستزراع السمكي \\
\hline * & 0,169 & عدد سنوات الخبرة في مجال الإستزراع السمكي \\
\hline ** & 0,383 & الدخل السنوي من الإنتاج السمكي \\
\hline ** & 0,380 & السعة الحيازية المبحوثين \\
\hline ** & 0,411 & منوسط إنتاج القفص \\
\hline * & 0,151 & مصادر المعرفة لاى مزارعي الأسماك \\
\hline * & 0,088 & الإتجاه نحو مهنة الإستزراع السمكي \\
\hline
\end{tabular}

يتضـح مـن جدول رقم (3) وجـود علاقـة إرتباطيـة معنويـة طرديـة بين متغيـر المستوى المعرفي لمربي الأسماك كمتغير تابع وبين كل من : أعمار المبحوثين، المستوى التعليمي، عدد أفراد الأسرة، عدد أفراد الأسرة العاملين في الإستزراع السمكي، الخبرة السمكية للمبحوثين، الدخل السنوي من الإنتاج السمكي، السعة الحيازية من الأقفاص العائكـة، متوسط إنتاج القفص، مصـادر المعلومات الزراعية السمكية للمبحوثين، إتجاه المبحوثين نحو الإستزراع السمكي ، وبهذا يمكن رفض الفرض الصفري أو الإحصائي وقبول الفرض الأصلي أو البحثي.

رابعاً: المشكلات التي تواجه مريي الأسماك المبحوثين من وجهه نظرهم:

ترجع أهمية دراسة المشكلات التي تواجه مربي الأسماك المبحوثين بهذه الدراسة إلى أن تضع أمام متخذي

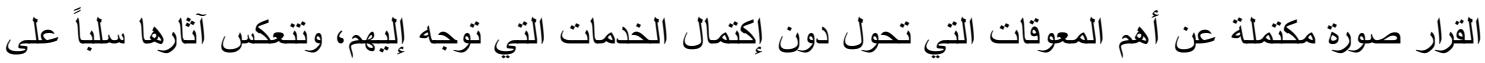


العطلية الإنتاجية بالنسبة للأسماك، وبالتالي نؤثز على العوائد التي يمكن أن تعود على المربي نتيجة حل هذه

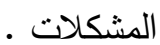

وقد أسفرت النتائج عن وجود ست مشكلات وهي المشكلات التي تكرر ذكرها من غالبية المبحوثين وكانت

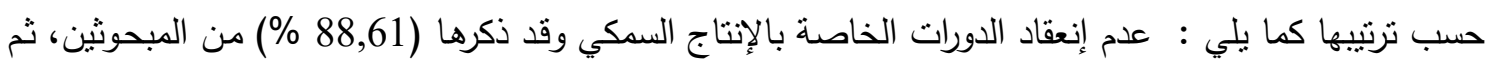

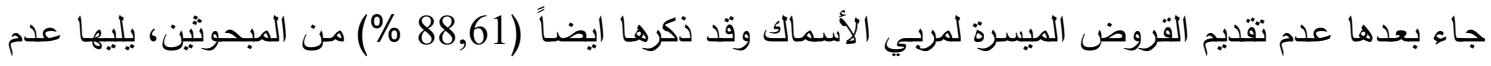

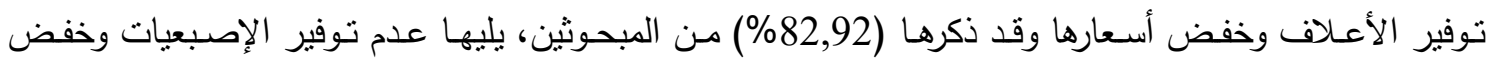
أسعارهاوقد ذكرها (74,79 \% من المبحوثين، ثم جاء بعدها عدم توفير المواد الأولية في الأسواق المحلية وقد ذكرها (69,10\%) من المبحوثين، وجاء بالترتيب الأخير لتلك المشكلات التمسك بتطبيق الروتين الحكومي وقداء ذكرها (43\%) من المبحوثين جدول رقم (16).

جدول رقم (4) : ترتيب المشكلات التي تواجه مريي الأسماك المبحوثين وفقاً لأهميتها النسبية بالنسبة لهم

\begin{tabular}{|c|c|c|c|}
\hline النسبة المئوية & 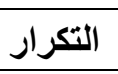 & المشكلات & التسلسل \\
\hline 88,61 & 109 & عدم إنعقاد الدروات الخاصة بالإنتاج السمكي & 1 \\
\hline 88,61 & 109 & عدم تقديم القروض الميسرة لمربي الأسماك & 2 \\
\hline 82,92 & 102 & عدم توفير الأعلاف ورخص أسعار ها & 3 \\
\hline 74,79 & 92 & عدم توفير الإصبعيات ورخص أسعار ها & 4 \\
\hline 69,10 & 85 & عدم توفر المواد الأولية & 5 \\
\hline 43,0 & 53 & التمسك بتطبيق الروتين الحكومي & 6 \\
\hline
\end{tabular}

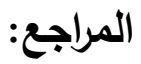

أولاً: المراجع باللغة العربية: أبو حطب، فؤاد، وسيد أحمد عثمان ، وآمال صادق. 1987. التقويم النفسي، مكتبة الأنجلو المصرية - القاهرة . أبو السعود، خيري حسن. 1987. الإرشاد الزراعي، التتظيم والتخطيط والتقيبم، مديرية التربية والتعليم، الجمهورية والتهية العبية اليمنية. إبراهيم، جمال الدين صالح علي. 1990. أساسيات رعاية الأسماك وإدارة المزرعة السمكية، الجزء الاول، كلية الطب البيطري، جامعة الزقازيق.

الخولي، حسين زكي. 1971. الإرشاد الزراعي ، دوره في تطوير الريف، دار الكتب الجامعية، الإسكندرية .

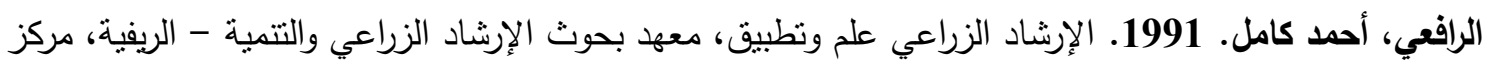
البحوث الزراعية، وزارة الزراعة. السيد، أحمد فؤاد حلمي، 1990. دراسة الإحتياجات التعليمية الإرشادية للزراع في مجال التسميد وصيانة - التربة بمنطقة إمتداد أبيس، محافظة الإسكندرية، رسالة ماجستير ، جامعة الإسكندرية. المنظمة العربية للتنمية الزراعية، 2011. الكتاب السنوي للإحصاءات الزراعية،الخرطوم، السودان.

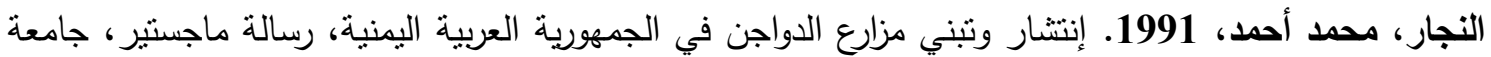




$$
\begin{aligned}
& \text { توق، محي الدين، يوسف قطامي، عبد الرحمن عدس. 2007. أسس علم النفس التزبوي، دار الفكر للنشر } \\
& \text { والتوزيع، عمان الأردن. } \\
& \text { جامع، محمد نبيل. 1975. المفتتح في علم الإجتماع، دار المطبوعات الجديدة،الإسكندرية . } \\
& \text { جلال، مسعد. 1985. القياس النفسي والمقاييس والإختبارات، دار الفكر العربي، القاهرة. } \\
& \text { حن، عبد الباسط محمد. 1990. أصول البحث الإجتماعي، مكتبة وهبه للطباعة والنشر ، القاهرة، مصر . } \\
& \text { رضوان، إسماعيل عبد الحميد أحمد. 1998. بعض العوامل المؤثرة على إنتشار مستحدثات الإستزراع السمكي، وهيه } \\
& \text { رسالة دكتوراة، كلية الزراعة، جامعة المنصورة. } \\
& \text { سيد أحمد، غريب محمد ـ 1989. تقييم وتتفيذ البحث الإجتماعي، دار المعرفة الجامعية، الإسكندرية. } \\
& \text { عمر، أحمد محمد، خيري أبو السعود، طه أبو شعيشع، أحمد الرافعي. 1973. المرجع في الإرشاد الزراعي، دار دار الإني }
\end{aligned}
$$

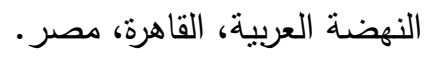

$$
\begin{aligned}
& \text { عمر، أحمد محمد . 1978. الإرشاد الزراعي، أوفسيت للطباعة، القاهرة. } \\
& \text { وزارة التخطيط والإنماء العراقية - دائرة التخطيط الزراعي. } 2009 .
\end{aligned}
$$

Hepher,B,1988.NutritionofPondfishes,CambridgeUniversity Press, Cambridge, New York.

Bloom, B. S., M. D. Englehart, E. J. Furst, W. H. Hill, and D. R. Krathwohl. 1956. Taxonomy educational goals, $\mathrm{H}$, Handbook, I: Cognitive Domain, New York, Longmans, Green, USA.

Royce,W.F.1995.Interoduction to the Practice of Fishery Science Academic Press. Inc-San Diego, California.

EL-Ghmrini,S.A.1998 Economic Evaluation of Farmers, Adoption for Raising Fish in Cages in Egyept. Ph.D. Thesis Zagazig University (Banha Branch).

\section{A Study of Some Variables Related to Knowledge Level of Fish Breeders of Gharraf River in Republic of Iraq}

\section{Abou Zaid Mohamed M . EL - Habbal, Souzan Ibrahim EL - Sayed EL- Sharbatly, Mustafa Lutfi Sabri}

Dept. of Agricultural Economic, Faculty of Agriculture (Saba Basha)- Alexandria University

ABSTRACT : This research is aims mainly to identify some of the variables associated with the level of knowledge of fish breeders in Gharraf River Basin in the Republic of Iraq.

We used personal interview to collect the research data of all fish farmers in floating cages in River Basin Garraf Iraq totaling 123 breeders, has represented the results using the following statistical analyies: Percentage, Percentage Distribution, Frequency tables, SMA, arithmetic mean and so as to 
show the contrast between the respondents. It also used to check the veracity of the hypotheses research all of the simple correlation coefficient for Pearson to study the relations questionnaire, between independent variables and the dependent variable, using the computer a program spss (statistical Package for the Social Sciences), The research results showed the following:

\section{First: personal characteristics and socio-economic and psychological connectivity fish breeders to respondents}

Ages associated with the percentage of respondents between the ages of $(25-39)$ years (48.8\%) and (39-53) years (22\%) and (53 years and over) about $(29.2 \%)$ of the total fish farmers surveyed. As for the educational level of the respondents, it was clear from the results of the respondents that $(30.9 \%)$ of the respondents with a low level of education, and (52\%) with average educational level , while (17\%) of the respondents; with high educationd level of the total fish farmers respondents; with regard to the number of family members it was clear from the results that (35\%) of those with small families, and $(57.7 \%)$ oflarge size those middel sized families while $(7.3 \%)$ of those with families big Alndjemua of total respondents; with respect to the number of family members working in the field of aquaculture study it showed that the number of family members working in the aquaculture of the first category percentage $(14.6 \%)$ and the number of family members working in the aquaculture of the second category amounted percentage $(43.1 \%)$, and the number of family members working in the aquaculture of the third category amounted to $(42.3 \%)$ of the total respondents, fish farmers, In connection with the expertise of the fish reaching the proportion of respondents, ranging from the number of years of experience between (1-11 years) (30.1\%), and number of years of experience ranging between (11-21) years $(43.9 \%)$, while the range of the number of years of experience (21 years and older) (26\%) of the total respondents, fish farmers As far as annual income from fish production it showed that those who have a low income accounted to (1.6\%), while middle income amounted to (76.4\%) and high income earners accounted to (22\%) of the total respondents, with respect to capacitive possessory floating fish cages the study showed that the percentage of fish farmers possession of respondents who have a small farm $(56.1 \%)$, and medium (25.2\%) and high (18.7\%) of the total respondents; The cage is associated with an average production of fish, the study showed that the percentage of educators with low production amounted to $(16.3 \%)$, while the percentage of those with average production (41.5\%), while the percentage of people with high production (42.3\%) of the total fish farmers surveyed; As for the sources of information farming and fishing to respondents, the study showed that the proportion of people with the level of the sources of low reached $(13 \%)$, and the percentage of people with sources medium was $(72.3 \%)$ while the percentage of people with sources of high $(13.8 \%)$ of the total respondents, and for the direction of the respondents about the percentage of aquaculture fish farmers with a negative trend (3.35\%) and neutral $(71.5 \%)$ and positive $(25.2 \%)$ of the respondents.

\section{Second: the knowledge level of the fish farmers of respondents}

The study showed that the proportion of people with low knowledge level was $(59.3 \%)$ while the percentage of people with cognitive level average 
$(30.1 \%)$, and the proportion of people with a high level of $(10.6 \%)$ of the total respondents to the fish farmers.

\section{Third: Breeders respondents}

The results showed a correlation significant positive correlation between the variable cognitive level for fish farmers as the dependent variable and between each of: Age of the respondents, educational level, number of family members, number of family members working in the aquaculture, experienced fish to respondents, the annual income from fish production, capacity of possessory of the cages, the average production of the cage, the sources of information for the fish farm respondents, the direction of the respondents towards aquaculture.

Fourth: the most important problems facing fish breeders' respondents from their point of view

The study showed the presence of six problems arranged as follows: sessions on production of fish (88.61\%) of the respondents, to providers soft loans to fish farmers mentioned (88.61\%) of the respondents providers feed and licenses $(82.92 \%)$ of the respondents, provision of fingerlings licenses and their price mentioned $(74.79 \%)$ of the respondents, provision of raw material $(69.10 \%)$ of the respondents, and red tape mentioned by $(43 \%)$ of the respondents. 